\title{
Mother Logit Analysis of Substitution Effects in Consumer Shopping Destination Choice
}

\author{
Harry Timmermans
}

Univerity of Technology Eindhoven, The Netherlands

University of Alberta, Edmonton, Canada

\author{
Aloys Borgers \\ Peter van der Waerden \\ University of Technology Eindhoven, The Netherlands
}

The feasibility of new shopping centers is largely related to their relative location and spending power in the trade area. Commercial developers, retailers, and retail planners need information about the likely impact of new retail developments on consumer choice behavior. Several types of consumer choice models have been applied to assess the effects of retail developments. However, most of these models are based on the so-called independence of irrelevant alternatives assumption, and the variables of interest are included in the models in some indirect manner. The purpose of this article is to demonstrate how substitution effects in consumer shopping behavior can be estimated as a function of marketing strategies or planning scenarios. We focus on the universal or "mother" logit model in a decompositional framework. The mother logit model represents a gencralization of conventional multinomial logit models in that the utility of alternatives depends not only on their attributes, but also upon the attributes of other alternatives in the choice set. These so-called cross-effects represent corrections on the utilities as predicted by the conventional multinomial logit model to account for substitution and other effects. The mother logit model was applied to predict the likely effects of a number of proposed actions to improve the attractiveness of some shopping centers in the Eindhoven region, The Netherlands. Rather than using attributes of shopping centers, possible planning actions were used to specify the utility function of the mother logit model. The model was estimated using choice data observed in hypothetical situations, created according to the principles of experimental design

Address correspondence to Professor Harry Timmermans, Marketing and Economic Analysis, University of Alberta, Edmonton, Alberta T6G 2R6, Canada. 
strategies. The results indicated that some planning actions affect the utility of other shopping centers significantly. Competition between shopping centers seemed to be stronger among centers belonging to the same hierarchical level and weaker among centers of different hierarchical levels, indicating the existence of substitution effects on consumer shopping center choice behavior.

\section{Introduction}

Site selection is one of the most pervasive problems in retailing. It is a complex problem with important implications for public policy decisions, commercial development, and retailer success. Retailers generally try to maximize market share by adopting a marketing mix strategy that favors their relative position in the market. Although marketing mix variables such as price, services, and product assortment may be easy to change, locational advantages or disadvantages are often more difficult to adjust. For example, a store's location vis-à-vis population concentrations, transportation networks, and competitors affects sales volumes that can be achieved. Commercial developers are primarily interested in the feasibility of their projects, but feasibility of new shopping centers is largely related to their relative location, the total spending power in the trade area, and the amount and type of competition. Public policy and planning authorities have a vested interest in the retail location because problem they wish to manage and integrate changes that might occur in the retailing system to alleviate possible ill effects on their existing commercial structure.

Thus, although the primary interests of retailers, commercial developers, and retail planners may differ considerably, all need information about the likely impact of new retail developments on consumer choice behavior to make more informed decisions. Models of consumer choice of shopping destinations increasingly play an important role in the evaluation of retail sites. The attraction of these models is due to their potential to provide managers and planners with detailed insights into the relative effectiveness of marketing strategies or planning scenarios, and forecasts of how consumers are likely to respond to such strategies or scenarios.

Several different models have been applied to practical site selection problems in retailing. These models differ in terms of levels of aggregation, specifications, underlying theories, data requirement, and the like. Regardless of modeling approach, however, most applied work in consumer choice of shopping centers or stores has been constrained by 2 important limitations: 1) an assumption that the trade of new stores or shopping centers will be captured from existing shopping centers in direct proportion to their attractiveness (the so-called Independence from Irrelevant Alternatives or IIA property (Luce, 1959)); and 2) the managerial relevance of many models is weakened either because variables of managerial interest are not included in models, or only are included in some indirect manner. In the latter case, additional operational assumptions are required to relate marketing strategies or planning sccnarios to the explanatory variables used in the model.

Potential solutions to these problems have been proposed by researchers in marketing, management science, urban planning, transportation science, economics, and environmental psychology. Thus, although more sophisticated models are 
available, there is little empirical literature to illustrate their application to consumer choice of shopping centers.

The purpose of this article, therefore, is to demonstrate how some recent developments in choice modeling can be combined to estimate substitution effects in consumer shopping center choice as a function of marketing strategies or planning scenarios. More specifically, we focus on the universal or "mother" logit model (McFadden, 1977) and use it in a decompositional framework.

To position our work, we first briefly summarize existing modeling approaches for store or shopping center choice. Then we discuss the principles underlying the mother logit model and compare it with some other models that avoid the IIAproperty. A fourth section illustrates the application of the model and presents the empirical findings that show that substitution effects may be present in consumer choice of shopping centers. A final section summarizes the findings of our study and makes recommendations for future research.

\section{Retail Models}

Many different models have been developed or applied to answer retailing questions related to changes in market share, consumer choice behavior, feasibility, sales volumes, and impact assessment (Davies and Rogers, 1984; Wrigley, 1988). Perhaps the simplest models are analogue models used to estimate sales potentials of new stores at new sites. These models are based on ad hoc rules to identify existing stores that are similar to a proposed store in as many respects as possible. The sales of such analogue stores are used to estimate potential sales of the new store. This approach is not based on an explicit theory of consumer shopping behavior, nor does it deal directly with competitive relationships between stores.

Another approach is to estimate the total demand in a market for the range of products to be sold using census data. The estimated demand is translated into sales per square foot for existing stores. Ad hoc assumptions are used to estimate the additional retail floorspace that could be supported by a market without reducing the average sales per square foot of existing stores below some critical threshold.

Multiple regression models represent a somewhat more systematic way to predict sales performance of stores. Sales (or sales per square foot) often are regressed against a (wide) range of store, site, and situation variables; trade area demographic and socioeconomic variables; and variables pertaining to local competitors. Such models do not provide a logically consistent basis for predicting market share (Naert and Weverbergh, 1981).

In contrast to these $a d$ hoc approaches, models are available that either explicitly or implicitly incorporate; 1) assumptions about consumer choice behavior; or 2) the competitive environment; and 3) provide logically consistent market share forecasts. Perhaps the best-known of these are gravity-type models, which include models based on one attraction and distance decay variable (e.g., Huff, 1963; Lakshmanan and Hansen, 1965), as well as extensions like the multiplicative competitive interactive and entropy-maximizing models (e.g., Gibson and Pullen, 1972; Jain and Mahajan, 1979; Timmermans, 1981; Achabal et al., 1982; Ghosh and McLafferty, 1982; Ghosh and Craig, 1983; Wilson, 1988). These models are based 
on aggregate expenditure or trip flows between residential zones and shopping centers. The flows are typically predicted to be a function of a shopping center's attractiveness measured by (e.g.) its floorspace and parking facilities and some distance or travel impediment measure.

Other models of consumer shopping choice behavior belong to the class of disaggregate discrete choice models, the best known of which is the multinomial logit (MNL) model (see e.g. Richards and Ben-Akiva, 1974; Recker and Stevens, 1976; Recker and Kostyniuk, 1978; Timmermans, 1984). Gravitational models can be reformulated as logit models that incorporate shopping center attractiveness and distance decay variables. Unlike gravitational models based on aggregate zonal flows, the parameters of multinomial logit models are estimated from discrete consumer shopping choices observed in real markets.

Finally, decompositional preference models have been applied to study consumer choice of shopping centers (e.g., Timmermans, 1982; Timmcrmans et al., 1984; Moore, 1988). The parameters of these models are estimated from consumer preference data collected under quasi-laboratory circumstances. Typically, store or shopping center attributes and a range of levels are identified. These attribute levels are combined into store descriptions according to principles from the design of statistical experiments. Consumers express or "state" their preferences for these store descriptions or attribute profiles. These stated preferences can be decomposed to identify part-worth utilities for the attribute levels. Typically, consumer choice bchavior is simulated by using an ad hoc deterministic "choice = highest preference" rule; or equally ad hoc, but sophisticated probabilistic choice rules.

Although the proceeding modeling approaches are based on different theoretical assumptions, measurement procedures, and estimation techniques, they have in common the so-called IIA property. Gravity-type models, MNL models, and many decompositional preference models assume that the probability of choosing shopping center $A$ relative to center $B$ is independent of the existence and characteristics of any other shopping center included in a consumer's choice set. The IIA property implies that a new shopping center or change in the attractiveness of an existing shopping center will draw trade from competing shopping centers in direct proportion to their market shares/attractiveness. This assumption is likely to be unrealistic, especially if shopping centers with similar characteristics compete for the same market. Under such circumstances one expects a new shopping center to draw trade more than proportionally from similar centers and less than proportionally from dissimilar centers because similar centers are substitutes. However, it is also possible for the market share of a shopping center or store to decrease less than proportionally as a result of new shopping development if agglomeration effects occur. In any case, more sophisticated retail choice models are required to describe consumer shopping center choice behavior more accurately than conventional models. In the next section, we describe the mother logit model and propose it as a possible candidate for a more accurate representation of choice behavior.

\section{Mother Logit and Other Non-IIA Models}

Before discussing the mother logit model, it might be relevant to place it in the wider context of various modeling strategies that have been developed during the last decade to accommodate violations of IIA. The IIA property of convention- 
al logit models can be violated if any of the following assumptions are violated: 1) the error terms of the utility function are independently and identically distributed; 2) a choice alternative's utility is a function of its attributes only and not a function of the attributes of other alternatives in the choice set; and 3) individuals process the attributes of interest simultaneously and not sequentially or hierarchically.

Most models that avoid the IIA property relax one or more of these assumptions. Thus, some non-IIA models allow for different variances and covariances among the error terms of the utility function. For example, the generalized extreme value (McFadden, 1980) and generalized probit models (Daganzo, 1979) belong to this class (see Currim, 1982, for an introduction to these models in a marketing context). To the authors' knowledge, none of these models have been applied to consumer shopping center choice. The relevance of these models for impact analysis may be limited because most require estimation of many parameters unrelated to marketing mix variables or retail planning scenarios. Exceptions include the perceptual interdependence model (Hausman and Wise, 1978) and Kamakura and Srivastava's (1984) model, which represent attempts to model the variance and covariance of the unmeasured components of utility using measured perceptions on various attributes, or (dis)similarities among the choice alternatives in the product space, respectively.

A second class of models avoids IIA by explicitly including some measure of (dis)similarity in the altcrnatives utility functions. (see, e.g., Batsell 1981; Meyer and Eagle, 1982; and Borgers and Timmermans, 1987, 1988). These models differ mainly in the specification of the similarity component. Fotheringham's $(1983,1988)$ competing destinations model is a gravity-type version of this approach. Although originally developed for application in a migration context, his model also can be applied to retail choice (Guy, 1987).

The third class of models circuments the IIA property by assuming hierarchical or sequential decision making processes. The best-known of these models are the elimination by aspects model (Tversky, 1972) and its preference tree version (Tversky and Sattath, 1979); factorial preference structures that represent a compromise between IIA and Elimination by Aspects (EBA) models (Moore, 1990) and the nested logit model. Nested logit addresses the substitution problem by grouping together similar choice alternatives at each level in an assumed decision hierarchy. Logit forms are used to predict marginal and conditional choice probabilities for each level of the decision hierarchy. As a result, substitution occurs only among choice alternatives belonging to the same level in the hierarchy.

Traditional applications of conjoint analysis do not explicitly handle asymmetric competitive effects. Most conjoint applications simulate consumer choices by assuming that the highest predicted preference alternative will be chosen. At the individual level, the introduction of new choice alternatives does not change the consumer's choice if preferences for these alternatives are less than preferences for existing alternatives. At the aggregate level, shifts in market shares reflect changes in the distribution of highest preference across consumers. Although some conjoint studies use probabilistic rules to forecast choice probabilities as a function of strength of preference for different choice alternatives, such rules are ad hoc. As well, typical choice rules satisfy the IIA property at the individual level, thereby denying the existence of substitution effects. 
Louviere and Woodworth (1983) proposed an experimental approach that observes choices directly. In common with traditional conjoint analysis, their approach requires one to generate attribute profiles of choice alternatives (e.g., descriptions of shopping centers). However, in contrast to traditional conjoint analysis, the attribute profiles are then placed into choice sets and choices rather than strengths of preference responses are observed. Designs for choice experiments are largely dictated by the model assumed to represent subjects' choice behavior. Choice experiments that satisfy the MNL model can be constructed by designing orthogonal fractonial factorial experiments. One can create choice sets either with a fixed number of choice alternatives or that vary in size and composition. In the latter case, one uses $2^{\mathrm{N}}$ or other block designs, in which each of the $\mathrm{N}$ profiles or choice alternatives are present or absent. Respondents select one and only one alternative from each choice set or possibly estimate the proportion of their total trips or expenditure that they would be likely to allocate to each choice alternative. The choices or allocations typically are aggregated into frequency counts across respondents to estimate choice probabilities. Various estimation techniques like maximum likelihood or minimum chi-square are used to estimate the parameters of MNL choice models given the observed choice data.

The IIA (or constant cross-substitution) property implies that pairwise choice probabilities will be independent of the presence of or variation in the attributes of other choice alternatives in consumer choice sets. Hence, one approach to avoid the IIA property is to create choice experiments that allow the utility of a choice alternative to depend upon the presence/absence of other options or changes in the attributes of the other alternatives in the choice set. One model that has this property is the universal or mother logit model.

Mother logit represents a generalization of conventional MNL models in that the utility of choice alternatives depends not only upon their attributes, but also upon the attributes of other alternatives in the choice set. Technically, this is accomplished by including additional constants and attribute effects in the specification of the utility function. These so-called cross-effects represent corrections on the utilities as predicted by the conventional MNL model to account for differences in choice set composition (e.g., competition, agglomeration, etc.). Significant cross-effects imply violations of the IIA property. Negative cross-effects indicate that the utility (hence, market share) of an alternative is significantly lower than that predicted by the II A model (e.g., due to similarity or substitution effects), whereas positive cross-effects indicate that an alternative's utility is significantly underestimated by the IIA model and should be corrected upwards (e.g., due to agglomeration or complementary effects). Both types of effects may violate the regularity condition of conventional MNL models. The Batsell and Polking (1985) model is similar to mother logit, but previous applications have been limited to modeling presence/absence effects. The Batsell and Polking (1985) model is a constant utility version of a presence/absence case of the mother logit model. A multiattribute extension of their model (Jain and Bass, 1989) represents a special case of attribute effects conditional on presence in the choice set.

Mother logit is thus similar in nature to the second class of models that circumvent the IIA property, the main difference being that it models cross-effects whereas other models in this class are based on some explicit (dis)similarity measure among choice alternatives. As a result, the mother logit model's asymptotic behavior is 
not logically consistent, whereas some other models (Batsell's model being an exception) are (e.g., Borgers and Timmermans, 1988).

Experimental design strategies that allow estimation of cross-effects are usually more complicated than designs for problems in which IIA is satisfied, but essentially the same principles can be applied. Availability effects can be estimated from choice experiment data if the choice sets are constructed according to an orthogonal fraction of a $2^{\mathrm{N}}$ design ( $\mathrm{N}$ being the number of choice alternatives in the choice set) that permits estimation of first order interactions. Attribute cross-effects can be estimated by creating choice sets in which the attributes of all alternatives are orthogonal to one another between and within alternatives. Thus, one selects orthogonal fractions of the $\mathrm{L}^{\mathrm{N} \times \mathrm{M}}$ factorial ( $\mathrm{L}$ is the number of attribute levels, $\mathrm{N}$ is the number of choice alternatives, and $M$ is the number of attributes) if the attributes of all alternatives have exactly the same number of levels. This principle also applies to the more general case of varying number of attribute levels and varying number of attributes per choice alternative (Louviere, 1986).

Random utility choice models typically assume that consumer choice can be represented as a function of attributes of choice alternatives. Applications require researchers to translate managerial actions into explanatory variables. In the next section, we show how to apply the mother logit model to an applied problem involving consumer choice of shopping center. Rather than using attributes of shopping centers, possible managerial and planning actions were used to specify the utility function. This allows us to cxamine substitution effects directly as a result of managerial and planning decisions (see also Louviere, 1984).

\section{An Application}

\section{Study Area and Design}

The 2 major municipalities in the Eindohoven region of The Netherlands are Eindhoven and Veldhoven. Both municipalities have developed proposals to improve the attractiveness of their main shopping centers. These proposals resulted from collaboration among commercial developers, retailers, and municipal planning authorities. In the Eindhoven case, consideration was being given to whether to build a new in-town shopping complex on a former hospital site. The complex would be integrated with a new music hall and abundant parking spaces in an underground parking garage. In the Veldhoven case, the municipality had just given approval for a major clothing store to operate in a former library. In addition, they were developing plans to improve the accessibility of the main shopping center by creating additional parking spaces. The present research project was concerned with predicting how the actions of competing shopping centers would affect the shopping choices of consumers in one specific neighborhood in the municipality of Veldhoven.

The data were collected in September 1988 based on random sample of 158 respondents who were responsible for shopping. For the present article only data on respondents' actual shopping behavior and choices observed in hypothetical situations were analyzed.

The choice experiment was developed as follows. First, the consumers' typical choice set was identified. Local knowledge and previous studies suggested that 
consumers in the study area mainly chose among 3 shopping centers: Veldhovencity-center, Eindhoven-city-center and Veldhoven-Burgemeester van Hoofflaan (a neighborhood center). Thus, these 3 shopping centers should always be choice alternatives in the experiment. Next, for each shopping center, a separate set of possible actions was envisaged. The actions tor "Veldhoven-city-center" were: 1) $10 \%$ increase of total floorspace; and 2) a $10 \%$ extension of the number of parking spaces. Possible actions for "Eindhoven-city-center" were: 1) a new major in-town hypermarket located close to the market square; 2) a $15 \%$ increase of parking costs; 3) 600 additional underground parking spaces; and 4) a $10 \%$ increase in floorspace for shops. As explained previously, these actions were actually being considered by the respective commercial developers, retailers, and planning authorities at the time of this study.

The actions for "Burgemeester van Hoofflaan" consisted of: 1) a diversification of shop types; 2) pedestrianization of a shopping street; and 3) the opening of a major appliance store. These actions were very hypothetical; because no actual plans had been made to change this shopping center at the time of the survey.

Each action was assigned 2 levels: it could be implemented or not. A fraction of the $2^{9}$ factorial was constructed to represent different combinations of actions. This design produced 16 choice sets consisting of a description of a combination of actions that each shopping center might take. The choice of "any other shopping center" was added to each choice set as a fourth option. Respondents evaluated each of the 16 choice sets one at a time. They were asked to allocate a fixed number of shopping trips among the 3 shopping centers and "any other" if the actions described in each choice set were to occur. Order of appearance of choice sets was randomized across respondents.

\section{Analyses and Results}

Individual trip allocations were aggregated across respondents to yield choice frequency data. Parameter estimates for the mother logit model are presented in Table 1 . Table 1 indicates that all main effects are statistically significant beyond the $5 \%$ probability level. The alternative-specific intercept is highest for "Burgemeester van Hoofflaan" shopping center and lowest for Eindhoven city center, which reflects respondents' tendency to shop less in Eindhoven. The opening of a magnet store seems to exert the most positive influence on "Eindhoven city-center" attractiveness, followed by creation of additional parking facilities and a $10 \%$ increase in retail floorspace. The parameter associated with a $15 \%$ increase in parking costs suggests that this policy would decrease the center's attractiveness and market share.

Similarly, Table 1 shows that an increase of the amount of retail floorspace would improve the attractiveness of the "Veldhoven city-center," and increasing the amount of parking by $10 \%$, although positive, is not statistically significant. Finally, the attractiveness of the Burgemeester van Hoofflaan would seem to benefit most from a diversification policy, followed by opening a major appliances store. Restricting this shopping street to pedestrians negatively affects its attractiveness, but the effect is not statistically significant at the $5 \%$ probability level.

Our choice experiment only allowed us to estimate interaction effects for Eindhoven city-center. Table 1 shows that only 2 interaction effects are statistically 
Table 1. Parameter Estimates and $t$ Values of the Universal Logit Model

\begin{tabular}{|c|c|c|}
\hline & Parameter Estimate & $t$ Value \\
\hline $\begin{array}{l}\text { Eindhoven city center (EHV) } \\
\text { Alt. specific coeff. }\end{array}$ & -1.3433 & -215.1309 \\
\hline $\begin{array}{l}\text { Main effects } \\
\text { 1. Opening magnet store } \\
\text { 2. } 15 \% \text { increase parking costs } \\
\text { 3. } 600 \text { additional parking spaces } \\
\text { 4. } 10 \% \text { increase retail floorspace }\end{array}$ & $\begin{array}{r}0.0335 \\
-0.0300 \\
0.0193 \\
0.0159\end{array}$ & $\begin{array}{r}5.3705 \\
-4.8108 \\
3.0858 \\
2.5406\end{array}$ \\
\hline $\begin{array}{l}\text { Interaction effects } \\
\begin{array}{l}1 \times 2 \\
1 \times 3 \\
1 \times 4 \\
2 \times 3 \\
2 \times 4 \\
3 \times 4\end{array}\end{array}$ & $\begin{array}{r}-0.0040 \\
0.0051 \\
-0.0118 \\
0.0041 \\
-0.0042 \\
0.0119\end{array}$ & $\begin{array}{r}-0.7063 \\
0.8946 \\
-2.0739 \\
0.7202 \\
-0.7419 \\
2.0914\end{array}$ \\
\hline $\begin{array}{l}\text { Veldhoven city center (VCC) } \\
\text { Alt. specific coeff. }\end{array}$ & 0.7094 & 230.7770 \\
\hline $\begin{array}{l}\text { Main effects } \\
10 \% \text { incrcasc floorspacc } \\
10 \% \text { more parking spaces }\end{array}$ & $\begin{array}{l}0.0241 \\
0.0037\end{array}$ & $\begin{array}{l}7.0239 \\
1.0693\end{array}$ \\
\hline $\begin{array}{l}\text { Burgemeester van Hoofflaan }(\mathrm{BvH}) \\
\text { Alt. specific coeff. }\end{array}$ & 0.9623 & 288.0714 \\
\hline $\begin{array}{l}\text { Main effects } \\
\text { Diversification of shops } \\
\text { Pedestrianization } \\
\text { Opening appliances store }\end{array}$ & $\begin{array}{r}0.1388 \\
-0.0054 \\
0.0401\end{array}$ & $\begin{array}{r}41.5503 \\
-1.6108 \\
12.0019\end{array}$ \\
\hline $\begin{array}{l}\text { Cross-effects (significant) } \\
\text { BvH diversification on EHV } \\
\text { BvH diversification on VCC } \\
\text { BvH appliance store on VCC. }\end{array}$ & $\begin{array}{r}0.0275 \\
-0.0233 \\
-0.0190\end{array}$ & $\begin{array}{r}4.4109 \\
-6.8106 \\
-5.5610\end{array}$ \\
\hline
\end{tabular}

significant: 1) the interaction between the opening of a magnet store and a $10 \%$ increase of floorspace for retailing; and 2) the interaction between 600 additional parking spaces and a $10 \%$ increase in retail floorspace. The former interaction effect has a negative sign, which is surprising because one usually assumes that shopping center attractiveness increases with increases in both additional floorspace and number of magnet stores. This result suggests that there may be a saturation point in shopping center attractiveness for this study area.

These main and interaction effects suggest a reasonable representation of the choice data, as provided by the simple MNL model. A more rigorous test, however, involves estimating and testing the cross-effects. If the cross-effects are significant, the IIA hypothesis should be rejected. Table 1 lists only 3 cross-effects that were significant at the 0.05 alpha level. These effects can be interpreted as follows. 1) A diversification policy in "Burgemeester van Hoofflaan" has a less than proportional effect on Eindhoven city-center, but a more than proportional effect on "Velhoven city center." 2) Likewise, the opening of a major appliances store in "Burgemeester van Hoofflaan" decreases the attractiveness of "Veldhoven citycenter" proportionally more than expected under the simple MNL model. Hence, 
the cross-effects provide uscful information regarding substitution effects among these shopping centers.

Having estimated the parameters of the choice model, the next step of the analysis involves assessing the goodness-of-fit of the estimated model. To do this, we used the estimated parameters to predict the choice probabilities for each choice set and the expected market share of the shopping centers. These predictions were then compared with observed choice data in the real world. Several goodness-offit measures were used to assess the results in order to avoid capitalizing on the specific properties of any particular measure.

First, model predictions were compared with observed choices under experimental conditions. As expected, the mother logit model reproduced the observed choices very well. The correlation coefficient is 0.999 ; Robinson's agreement measure, which depicts the degree of deviance from a perfect linear relation through the origin, is 1.0 ; the standardized root mean square is 0.02 and the standardized mean absolute error is only 0.016 .

Data on observed choices were obtained by asking respondents where they shop. Consumer choices were predicted by the mother logit model and compared with these observed choices. Although the goodness-of-fit was slightly lower in this case, the measures were still very high. For example, the Pearson correlation coefficient was 0.983 , Robinson's agreement measure was 0.99 , the standardized root mean square was 0.127 , and the standardized mean absolute error was only 0.127 .

To examine the impact of the cross-effects on the predictive power of the model, the mother logit model was compared with the conventional MNL model. This comparison indicated that the additional parameters significantly improved the predictive power of the model beyond the 0.05 level.

\section{Conclusion and Discussion}

In this article, we applied the mother logit model to analyze and predict consumer shopping center choice. The mother logit model represents a logically consistent extension of traditional multinomial logit models that avoids the IIA property. Our results indicated that the mother logit model reproduced the observed experimental choices very well, and it also predicted well the respondent-reported choices. However, it should be noted that despite a statistically significant difference, the MNL model performed only slightly less well.

If the results of the present study can be generalized to other regions and consumer groups, this study may have implications for retailing practice. As most models of consumer shopping center choice possess the IIA property, impact and feasibility assessments are based on the assumption that new retail development will draw trade from existing shopping centers in direct proportion to their attractiveness. The present study suggests, however, that competition between shopping centers is stronger among centers belonging to the same hierarchical level and weaker among centers of different hierarchical levels. This implies that conventional models may overpredict the sales volume of a new shopping center and underpredict the effects of the introduction of new retailing facilities on existing, lower level centers. Thus, if onc relics on traditional model predictions, a proposal may be regarded as feasible, whereas in reality it would not be (of course, the latter depends on the difference between sales and threshold, and differences in predictions be- 
tween model structures). Likewise, the negative effects on sales levels of existing lower order shopping centers may be considered negligible, whereas in reality such effects may be larger than predicted by IIA-type models. It should be emphasized that these prediction deviances do not result from inherent uncertainties associated with model use (e.g., due to sample size, temporal stability, etc.), but directly result from the theoretical assumptions underlying conventional models.

In the present study, the difference in predictive power between the mother logit model and the MNL model, although statistically significant, was relatively small and perhaps not managerially significant. Yet, in terms of modeling strategy, it is important to test for violations of IIA. Hence, we suggest that one designs experiments such that the parameters of mother logit models can be estimated. If the estimation results show that the cross-effects are nonsignificant, one still can safely use conventional MNL models. If one's design does not permit estimation of cross-effects, model predictions may be structurally invalid if the cross-cffects are actually significant. The mother logit model provides managers with more detailed information about the competitive structure of the shopping centers, even in cases in which the simple MNL model fits well. It would be useful to know whether the results of the present study generalize to other contexts, and how sensitive they might be to temporal and environmental changes.

\section{References}

Achabal, D., Gorr, W. L., and Mahajan, V., MULTILOC: A Multiple Store Location Decision Model. Journal of Retailing 58 (1982): 5-25.

Batsell, R. R., A Multiattribute Extension of the Luce Model which Simultaneously Scales Utility and Substitutability. Working paper for a Conference at Quail Roost. 1981.

Batsell, R. R., and Polking, J. C., A New Class of Market Share Models. Marketing Science 4 (1985): 177-198.

Borgers, A. W. J., and Timmermans, H. J. P., Choice Model Specification, Substitution and Spatial Structure Effects: A Simulation Experiment. Regional Science and Urban Economics 17 (1987): 29-47.

Borgers, A. W. J., and Timmermans, H. J. P., A Context-Sensitive Model of Spatial Choice Behaviour, in Behavioural Modelling in Geography and Planning. R. G. Golledge and H. J. P. Timmermans, eds., Croom Helm, London. 1988, pp. 159-78.

Currim, I. S., Predictive Testing of Consumer Choice Models Not Subject to Independence of Irrelevant Alternatives. Journal of Marketing Research 19 (1982): 208-223.

Daganzo, C., Multinomial Probit: The Theory and its Applications to Demand Forecasting. New York, Academic Press. 1979.

Davies, R. L., and Rogers, D. S. (cds.), Store Location and Store Assessment Research. Chichester, John Wiley. 1984.

Fotheringham, A. S., A New Set of Spatial Interaction Models: The Theory of Competing Destinations. Environment and Planning A, 15 (1983): 15-36.

Fotheringham, A. S., Consumer Store Choice and Choice Set Definition. Marketing Science, 7 (1988): 299-310.

Ghosh, A., and Craig, C. S., Formulating Retail Location Strategy in a Changing Environment. Journal of Marketing 47 (1983): 56-68.

Ghosh, A., and McLafferty, S., Locating Stores in Uncertain Environments: A Scenario Planning Approach. Journal of Retailing 58 (1982): 5-22.

Gibson, M., and Pullen, M., Retail Turnover in the East-Midlands: A Regional Application of a Gravity Model. Regional Studies 6 (1972): 183-196. 
Guy, C. M., Recent Advances in Spatial Interaction Modelling: An Application to the Forecasting of Shopping Travel. Environment and Planning A 19 (1987): 173-186.

Hausman, J., and Wise, D., A Conditional Probit Model for Qualitative Choice: Discrete Decisions Recognizing Interdependence and Heterogeneous Preferences. Econometrica 46 (1978): 403-426.

Huff, D. L., A Probabilistic Analysis of Consumer Spatial Behavior, in Emerging Concepts in Marketing. W. S. Decker, ed., Chicago, American Marketing Association. 1963, pp. 443-461.

Jain, A. K., and Bass, F. M., Effect of Choice Set Size on Choice Probabilities: An Extended Logit Model. International Journal of Research in Marketing 6 (1989): 1-11.

Jain, A. K., and Mahajan, V., Evaluating the Competitive Environment in Retailing Using Muliplicative Competitive Interactive Models. in Research in Marketing. J. N. Sheth, ed., Greenwich, CT, JAI Press. 1979, pp. 217-235.

Kamakura, W. A., and Srivastava, R. K., Predicting Choice Shares Under Conditions of Brand Interdependence. Journal of Marketing Research 21, pp. 420-435.

Lakshmanan, T. R., and Hansen, W. G., A Retail Market Potential Model. Journal of the American Institute of Planning 31 (1965): 134-143.

Louviere, J. J., Using Discrete Choice Experiments and Multinomial Logit Models to Forecast Trial in a Competitive Retail Environment: A Fast Food Restaurant Illustration. Journal of Retailing 60 (1984): 81-107.

Louviere, J. J., A Conjoint Model for Analyzing New Product Positions in a Differentiated Market with Price Competition. Advances in Consumer Research 13 (1986): 375-380.

Louviere, J. J., and Woodworth, G. G., Design and Analysis of Simulated Choice or Allocation Experiments: An Approach Based on Aggregate data. Journal of Marketing Research 20 (1983): 350-367.

Luce, R., Individual Choice Behavior: A Theoretical Analysis. Wiley, New York. 1959.

McFadden, D., Econometric Models of Probabilistic Choice. Journal of Business 53 (1980): 513-529.

McFadden, D., Tye, W., and Train, K., An Application of Diagnostic Tests for the Irrelcvant Alternatives Property of the Multinomial Logit Model. Transportation Research Record 637 (1977): 39-46.

Meyer, R. J., and Eaglc, T. C., Context-Induced Parameter Instability in a Disaggregate Stochastic Model of Store Choice. Journal of Marketing Research 19 (1982): 62-71.

Moore, L., Stated Preference Analysis and New Store Location. in Store Choice, Store Location \& Market Analysis, N. Wrigley, ed., Routledge, London. 1988. pp. 203-225.

Moore, W. L., Factorial Preference Structures. Journal of Consumer Research 17 (1990): 94-104.

Naert, Ph., and Weverbergh, M., On the Prediction Power of Market Share Attraction Models. Journal of Marketing Research 18 (1981): 146-154.

Recker, W., and Kostyniuk, L., Factors Influencing Destination Choice for the Urban Grocery Shopping Trip. Transportation 7 (1978): 19-33.

Recker, W., and Stevens, R., Attitudinal Models of Modal Choice: The Multinomial Case for Selected Non-Work Trips. Transportation 5 (1976): 355-375.

Richards, M., and Ben-Akiva, M., A Simultaneous Destination and Mode Choice Model for Shopping Trips. Transportation 3 (1974): 188-192.

Timmermans, H. J. P., Multiattribute Shopping Models and Ridge Regression Analysis. Environment and Planning $A 13$ (1981): 43-56.

Timmermans, H. J. P., Consumer Choice of Shopping Centre: An Information Integration Approach. Regional Studies 16 (1982): 171-182.

Timmermans, H. J. P., Discrete Choice Models versus Decompositional Multiattribute Preference Models: A Comparative Analysis of Model Performance in the Context of 
Spatial Shopping Behaviour, in Discrete Choice Models in Regional Science. D. E. Pitfield, ed., Pion, London. 1984, pp. 88-102.

Timmermans, H. J. P., van der Heijden, R. E. C. M., and Westerveld, H., Decision Making Between Multiattribute Alternatives: A Model of Spatial Shopping Behavior Using Conjoint Measurements. Environment and Planning A 16 (1984): 377-387.

Tversky, A., Elimination by Aspects: A Theory of Choice. Psychological Review 79 (1972): 281-299.

Tversky, A., and Sattath, S., Preference Trees. Psychological Review 86 (1979): 542-593.

Wilson, A. G., Store and Shopping-Centre Location and Size: A Review of British Research and Practice, in Store Choice, Store Location \& Market Analysis, N. Wrigley, ed., Routledge, London. 1988. pp. 160-87.

Wrigley, N. (ed.), Store Choice, Store Location \& Market Analysis, Routledge, London. 1988. 